\title{
Effectiveness and Safety of Abatacept in Moderate to Severe Rheumatoid Arthritis
}

\author{
Cortejoso-Fernández Lucía ${ }^{1}$, Romero-Jiménez Maria Rosa ${ }^{1}$, Pernía-López María Sagrario ${ }^{1}$, Montoro-Álvarez María ${ }^{2}$, \\ Sanjurjo-Sáez María ${ }^{1}$ \\ ${ }^{1}$ Pharmacy Department, Hospital General Universitario Gregorio Marañón, Madrid, Spain. \\ ${ }^{2}$ Rheumatology Department, Hospital General Universitario Gregorio Marañón, Madrid, Spain.
}

Received, August 4, 2011; Revised, October 27, 2011; Accepted, November 28, 2011; Published, December 10, 2011.

\begin{abstract}
Purpose: Abatacept was approved in our hospital by the Pharmacy and Therapeutics Committee for treatment of moderate to severe rheumatoid arthritis (RA) in adult patients with inadequate response or intolerance to disease modifying antirheumatic drugs (DMARDs), including at least one antitumour necrosis factor (anti-TNF). The objectives of this study were to analyze compliance with our protocol and to evaluate effectiveness and safety of abatacept in our patients. Methods: We performed a descriptive longitudinal study of patients with RA treated with abatacept between August 2008 and May 2010 in our day care unit. We reviewed clinical records and recorded the following data: sex, age, weight, year of diagnosis, previous antirheumatic treatments and reasons for withdrawal of anti-TNFs, indication for abatacept, dose and date of administration, Disease Activity Score (DAS28) and adverse events. Effectiveness was evaluated using the European League Against Rheumatism (EULAR) criteria. Results: We recruited 16 patients. Mean follow-up time was 10.4 (SD: 6.1) months. All patients had been previously treated with DMARDs, including at least one anti-TNF, and the mean dose of abatacept was 9.4 (SD: 1.4) $\mathrm{mg} / \mathrm{kg}$. During the first 6 months of treatment, 11/16 of patients experienced a decrease in their DAS28 value, but only 5/16 achieved a satisfactory response. Dyspnea was the most frequent adverse event (7/16), followed by fatigue and asthenia (6/16) and dry skin (5/16). Conclusions: The indication for abatacept in our hospital complied with the protocol approved by the Pharmacy and Therapeutics Committee. Only 5/16 of patients achieved a satisfactory response; however, it should be noted that these patients had moderate to severe RA that was refractory to other treatments. Adverse reactions were consistent with those described in the summary of product characteristics. Further studies with larger cohorts are needed to analyze the longterm safety and effectiveness profile in clinical practice.
\end{abstract}

This article is open to POST-PUBLICATION REVIEW. Registered readers (see "For Readers") may comment by clicking on ABSTRACT on the issue's contents page.

\section{INTRODUCTION}

Rheumatoid arthritis (RA) is an autoimmune chronic inflammatory disease that affects 0.5 $1.0 \%$ of adults, mainly women and the elderly(1). It consists of inflammation and pain in the joints and can cause extra-articular problems such as anemia and rheumatoid nodules. The disease progresses until it produces lesions that are difficult to treat(2).

Treatment of RA includes a wide variety of drugs, which can be classified in two groups: a) nonsteroidal anti-inflammatory drugs (NSAID), which control symptoms by decreasing pain and inflammation, and b) disease modifying antirheumatic drugs (DMARD), e.g., methotrexate, sulfasalazine and leflunomide, which aim to achieve disease remission(1).

Biological therapy (BT) has become an important option in the last decade. The first molecules to be incorporated in clinical practice were the anti-tumour necrosis factors (anti-TNF) etanercept, infliximab and adalimumab. These were followed by newer agents with different mechanisms of action, namely, rituximab (a monoclonal antibody that depletes B lymphocytes) and abatacept (a protein that selectively modulates the co-stimulation of $\mathrm{T}$ lymphocytes)(3).

BT modifies disease progress, improves the efficacy profile of DMARDs, and is useful in non-responders(2). However, these treatments have a maximum and short-term effect(4). The most recently developed molecules include tocilizumab, golimumab and certolizumab. Abatacept is a fusion protein that consists of the extracellular domain of human cytotoxic T-

Corresponding Author: Lucía Cortejoso Fernández, Hospital General Universitario Gregorio Marañón, Spain, Email: lucia.cortejoso@salud.madrid.org 
lymphocyte-associated antigen 4 (CTLA-4) linked to a modified $\mathrm{Fc}$ portion of human immunoglobulin G1 (IgG1). Abatacept selectively modulates a key costimulatory signal required for full activation of $\mathrm{T}$ lymphocytes expressing CD28(5). It inhibits the binding of CD80 and CD86 molecules on the surface of antigenpresenting cells to the $\mathrm{CD} 28$ receptor on $\mathrm{T}$ lymphocytes and decreases activation and proliferation of $\mathrm{T}$ lymphocytes, secretion of proinflammatory cytokines and production of autoantibodies.

Randomized double-blind controlled trials have shown abatacept to be effective in the control of signs and symptoms by slowing down radiological progression of joint damage in refractory RA patients(6).

However, response to treatment has to be evaluated carefully and frequently(1). Given experience with other biological drugs, the most important safety concerns with abatacept involve a higher incidence of infection and neoplasm(68).

Despite the obvious improvement in the treatment of rheumatic diseases afforded by biological agents, it is important to avoid indiscriminate use, due to expense, lack of information about long-term safety and variability in response(9).

Abatacept was approved by the Pharmacy and Therapeutics Committee of our hospital for the treatment of moderate to severe RA in adult patients with inadequate response or intolerance to other DMARDs, including at least one antiTNF.

Our objectives were to analyze adjustment to the protocol approved by the Pharmacy and Therapeutics Committee and to evaluate the safety and effectiveness profile of abatacept in our patients. This is the first study, to our knowledge, to analyze adjustment to a protocol approved and evaluate indication for abatacept in clinical practice.

\section{METHODS}

We performed a descriptive longitudinal study in a 1500-bed general hospital. The study population comprised patients with RA treated with abatacept between August 2008 and May 2010 in the day care unit.

Clinical records were reviewed to generate a database comprising the following variables: sex, age, weight, year of diagnosis, previous antirheumatic treatments and cause of withdrawal of anti-TNFs, indication for abatacept, dose and date of administration, Disease Activity Score
(DAS28) and adverse events. Doses and dates of administration were obtained from an electronic prescription program (Visual Limes, Valencia, Spain).

RA was classified as severe or moderate depending on the determination of DAS28, rheumatoid factor (RF), anti-cyclic citrullinated peptide antibodies (anti-CCP), bone erosion, C reactive protein (CRP), erythrocyte sedimentation rate (ESR) and the Health Assessment Questionnaire (HAQ).

Adherence to the dosage set out in the summary of product characteristics (10) was checked $(10 \mathrm{mg} / \mathrm{kg}$ at weeks 0,2 and 4 , then every 4 weeks thereafter). Dose was adjusted for body weight, as follows: patients $<60 \mathrm{~kg}, 500 \mathrm{mg}$; patients $\geq 60 \mathrm{~kg}$ and $\leq 100 \mathrm{~kg}, 750 \mathrm{mg}$; and patients $>100 \mathrm{~kg}, 1000 \mathrm{mg}$. A dose was considered an overdose or underdose when it was greater or lower than the weight-adjusted dose. An administration delay $\leq 7$ days was defined as delay, a delay $>7$ days was defined as temporary withdrawal, and withdrawal of abatacept due to lack of effectiveness or toxicity was defined as definitive withdrawal.

Effectiveness was evaluated using the European League Against Rheumatism (EULAR) criteria(11), which take into account both the degree of improvement in the disease and the recent situation of the patient. They use the DAS28 value(12), which includes acute phase reactants, number of swollen and tender joints and physician's visual analogue scale. DAS28 was calculated at the beginning of treatment with abatacept and after 6 months of treatment. A satisfactory response was defined as complete remission of the disease or sufficient response even if not complete; an unsatisfactory response was defined as absence of improvement.

\section{RESULTS}

The study population comprised 16 patients (15/16 women). Mean age was 50 (SD: 13.6) years at the beginning of the treatment and mean time of disease progression was 14 (SD: 6.3) years. RA was severe in 11/16 of patients and moderate in $5 / 16$. Mean follow-up time was 10.4 (SD: 6.1) months.

All patients had been previously treated with DMARDs. As for anti-TNFs, 11/16 had received infliximab, although treatment was withdrawn due to toxicity in 7 of them, lack of effectiveness in 3 and personal reasons in one patient. Etanercept was administered to $11 / 16$, although 8 of them stopped due to lack of effectiveness and 3 due to toxicity. Adalimumab had been 
administered in $7 / 16$; it was stopped due to ineffectiveness in 5 of them and toxicity in 2 . Rituximab was also administered in $12 / 16$ of patients.

The mean dose of abatacept was 9.4 (SD: 1.4) $\mathrm{mg} / \mathrm{kg}$, and in $9 / 16$ of patients the first dose was lower than the weight-adjusted dose (115.6 [SD: 119.0] mg less). In these patients, the dose was increased depending on their progress. Dose was sometimes higher than recommended in $2 / 16$ of patients, in whom the difference with the recommended dose was 150.0 (SD: 141.4) $\mathrm{mg}$. Only $2 / 16$ had a delay in some administrations (4 [SD: 0] days). Temporary withdrawal was necessary in 4/16 due to bariatric and orthopedic surgeries, infection and neutropenia, and definitive withdrawal was required in $6 / 16$ due to lack of effectiveness.

DAS28 decreased during the first 6 months of treatment in 11/16 of patients, but only 5/16 achieved a satisfactory response based on the EULAR criteria. Overall, 3/16 did not respond to treatment and suffered an increase in DAS28 and 2/16 did not have any variation in DAS28 (Table $1)$.

\begin{tabular}{|c|c|}
\hline Initial DAS28 & DAS28 after 6 months \\
\hline 5.1 & 3.1 \\
\hline 2.6 & 1.5 \\
\hline 2.8 & 2.9 \\
\hline 2.6 & 3.0 \\
\hline 4.9 & 4.4 \\
\hline 5.4 & 4.0 \\
\hline 4.3 & 3.7 \\
\hline 3.7 & 2.2 \\
\hline 2.3 & 1.0 \\
\hline 2.7 & 2.5 \\
\hline 2.8 & 2.8 \\
\hline 2.3 & 3.6 \\
\hline 3.4 & 2.4 \\
\hline 5.2 & 2.1 \\
\hline 3.4 & 2.2 \\
\hline 2.8 & 2.8 \\
\hline
\end{tabular}

Adverse events are shown in Table 2 . Dyspnea was the most frequent adverse event (7/16), followed by fatigue and asthenia (6/16) and dry skin $(5 / 16)$. In $2 / 16$ of patients, abatacept was temporarily withdrawn due to development of toxicity (infection and neutropenia).

\section{DISCUSSION}

The indication for abatacept in our hospital complies with the protocol approved by the
Pharmacy and Therapeutics Committee, since it was administered in patients with moderate to severe RA who had not responded to DMARDs and at least one anti-TNF.

The mean administered dose of abatacept was slightly lower than the recommended dose (9.4 $\mathrm{mg} / \mathrm{kg}$ compared to $10 \mathrm{mg} / \mathrm{kg}$ ), as physicians prescribed an initial dose that was lower than that recommended in the summary of product characteristics in more than half of the patients(10). This first dose was increased in the following administrations depending on response. Only two patients suffering very severe RA in whom treatment with abatacept was not effective occasionally received a higher than approved dose. Treatment was finally stopped in these two patients and in four more due to lack of effectiveness. Temporary withdrawal of the drug was totally justified in those patients who underwent surgery and who developed adverse reactions.

Only $5 / 16$ of patients achieved a satisfactory response with abatacept. However, in 11/16, the DAS28 value decreased. Patient management is often difficult, as abatacept is normally used in patients with moderate to severe RA progressing over a long period and with an inadequate response to other treatments.

The adverse reactions recorded were consistent with those described in the summary of product characteristics(10). The most frequent adverse events were dyspnea, fatigue and asthenia, skin and eye dryness, mouth ulceration, infections and abdominal pain. None of the patients suffered infusion reactions, as described in the study by Genovese et al $(13,14)$. However, one patient developed post-treatment lymphocytosis, and this was considered possibly related to the drug. Our results are consistent with the recent meta-analysis published by Singh et al on toxicity caused by biological agents(14) and also with reviews on the toxicity profile of abatacept in $\operatorname{RA}(15,16)$. None of our patients developed tuberculosis or neoplasms, as found in the review by Storage et al(17). However, patients with respiratory disease require special attention, since administration of abatacept has been associated with a higher risk of respiratory toxicity(18). A higher incidence of neoplasms during treatment with abatacept is not well probed since some studies have not found statistically significant differences in the incidence between the placebo group and the group receiving abatacept(19-21). 


\begin{tabular}{ll}
\hline Table 2. Adverse events & \\
\hline Toxicity & No. of patients \\
\hline Vascular disorders & 2 \\
- Hypertension & 1 \\
- Hot flushes & \\
Blood and lymphatic system disorders & 1 \\
- Neutropenia & 1 \\
- Anemia & 1 \\
- Lymphopenia & 1 \\
- Lymphocytosis & \\
Nervous system disorders & 2 \\
- Headache & \\
Eye disorders & 1 \\
- Conjunctivitis & 3 \\
- Eye dryness & 1 \\
Ear and labyrinth disorders & \\
- Vertigo & 7 \\
Respiratory, thoracic and mediastinal disorders & 2 \\
- Dyspnea & \\
- Thoracic pain & 3 \\
Gastrointestinal disorders & 2 \\
- Abdominal pain & 4 \\
- Diarrhea & \\
- Mouth ulceration & 3 \\
Skin and subcutaneous tissue disorders & 5 \\
$\quad$ - Rash & 2 \\
- Dry skin & 1 \\
- Skin ulceration & 3 \\
Musculoskeletal and connective tissue disorders & 3 \\
- Arthralgia & 2 \\
Infections & 1 \\
- Upper respiratory tract infections & \\
- Lower respiratory tract infections (pneumonia) & \\
- Urinary tract infections & \\
- Tonsillitis & \\
General disorders & \\
- Fatigue and asthenia & \\
- Influenza-like illness & \\
Reproductive system disorders & \\
- Amenorrhea & \\
\hline$\quad$ & \\
\hline
\end{tabular}

There are several options for the treatment of RA, thanks to the increasing availability of biological agents(22). A number of studies published in the last year have carried out indirect comparisons of the efficacy of biological therapies for RA, and all of them have found these agents to be similarly efficacious(22-24). However, in the study by Leffers et al(25), who compared the efficacy of abatacept and tocilizumab, decreases in DAS28 values were similar between both drugs, although a more rapid fall in C-reactive protein values was seen in patients treated with tocilizumab. Therefore, application of these agents should depend on safety and cost-effectiveness. With regard to the toxicity profile of biological antirheumatic agents, a meta-analysis revealed that abatacept and anakinra were associated with a lower risk of severe adverse events. Abatacept was less likely to be associated with serious infections than infliximab and tocilizumab and less likely than infliximab to produce withdrawals due to toxicity(26). In the study by Curtis et al(27) the rate of hospitalized infections was higher for infliximab than for abatacept in RA patients. During the last year, two health economics modelling studies performed in two different countries (Italy and Spain) reported the same result: abatacept appears to be more cost-effective than rituximab in patients with an insufficient response to anti-TNF agents $(28,29)$.

The main limitations of our study are its small sample size - abatacept is used in advanced stages of the disease - and the absence of a control group. Most of the patients included in the study were receiving concomitant medication 
(methotrexate, corticosteroids, non-steroidal antiinflammatory drugs, gastroprotective agents, vitamins, calcium, iron), and this could have played a role in efficacy and/or toxicity, i.e. patients treated with corticosteroids could be at a higher risk of developing infections.

Further studies are needed in order to analyze the long-term effectiveness and safety profile in clinical practice.

\section{ACKNOWLEDGEMENTS}

The authors would like to thank Thomas O'Boyle for editorial assistance.

The authors have indicated that they have no conflicts of interest regarding the content of this article.

\section{REFERENCES}

1. Scott DL, Wolfe F, Huizinga TW. Rheumatoid arthritis. Lancet. Sep 25;376(9746):1094-108.

2. Juan Mas A. La terapia biológica en las enfermedades reumáticas. Medicina Balear, 2008; 3, 11-16.

3. Gómez Centeno T. Rituximab y abatacept en la artritis reumatoide. Reumatol Clin, 2009; 5, 77-81.

4. Pablos Álvarez JL. Nuevas dianas terapéuticas en artritis reumatoide. Reumatol Clin, 2006; 2, 9-12.

5. Sharpe AH, Abbas AK. T-cell costimulation-biology, therapeutic potential, and challenges. $\mathrm{N}$ Engl J Med. 2006 Sep 7;355(10):973-5.

6. Goecke A. Abatacept, nueva alternativa dentro de la familia de las terapias biológicas. Reumatología, 2007; 23, 12-18.

7. Ellerin $\mathrm{T}$, Rubin RH, Weinblatt ME. Infections and anti-tumor necrosis factor alpha therapy. Arthritis Rheum. 2003 Nov;48(11):3013-22.

8. Listing J, Strangfeld A, Kary S, Rau R, von Hinueber U, Stoyanova-Scholz M, et al. Infections in patients with rheumatoid arthritis treated with biologic agents. Arthritis Rheum. 2005 Nov;52(11):3403-12.

9. Gibbons LJ HK. Biologic therapy for rheumatoid arthritis: clinical efficacy and predictors of response. BioDrugs. 2009;23(2):111-24.

10. European Medicines Agency. European Public Assessment Reports: Abatacept Product Information.

http://www.ema.europa.eu/docs/en_GB/document library/EPAR_-

_Product_Information/human/000701/WC500048

935.pdf. Revised September 9, 2010. Accessed March 15, 2011.

11. Reumatología SEd. Actualización de la Guía de práctica clínica para el manejo de la Artritis Reumatoide en España. Marzo 2007.

12. Wells G, Becker JC, Teng J, Dougados M, Schiff M, Smolen J, et al. Validation of the 28-joint Disease Activity Score (DAS28) and European
League Against Rheumatism response criteria based on C-reactive protein against disease progression in patients with rheumatoid arthritis, and comparison with the DAS28 based on erythrocyte sedimentation rate. Ann Rheum Dis. 2009 Jun;68(6):954-60.

13. Genovese MC, Becker JC, Schiff M, Luggen M, Sherrer Y, Kremer J, et al. Abatacept for rheumatoid arthritis refractory to tumor necrosis factor alpha inhibition. N Engl J Med. 2005 Sep 15;353(11):1114-23.

14. Singh JA, Wells GA, Christensen R, Tanjong Ghogomu E, Maxwell L, Macdonald JK, et al. Adverse effects of biologics: a network metaanalysis and Cochrane overview. Cochrane Database Syst Rev.2:CD008794.

15. Maxwell LJ, Singh JA. Abatacept for rheumatoid arthritis: a Cochrane systematic review. J Rheumatol. Feb;37(2):234-45.

16. Khraishi M, Russell A, Olszynski WP. Safety profile of abatacept in rheumatoid arthritis: a review. Clin Ther. Oct;32(11):1855-70.

17. Storage SS, Agrawal H, Furst DE. Description of the efficacy and safety of three new biologics in the treatment of rheumatoid arthritis. Korean J Intern Med. Mar;25(1):1-17.

18. Miller KL, Sawitzke AD, Doane J. Abatacept and serious respiratory infections in patients with previous lung disease. Clin Rheumatol. 2008 Dec;27(12):1569-71.

19. Weinblatt M, Combe B, Covucci A, Aranda R, Becker JC, Keystone E. Safety of the selective costimulation modulator abatacept in rheumatoid arthritis patients receiving background biologic and nonbiologic disease-modifying antirheumatic drugs: A one-year randomized, placebo-controlled study. Arthritis Rheum. 2006 Sep;54(9):2807-16.

20. Kremer JM, Dougados M, Emery P, Durez P, Sibilia J, Shergy W, et al. Treatment of rheumatoid arthritis with the selective costimulation modulator abatacept: twelve-month results of a phase iib, double-blind, randomized, placebo-controlled trial. Arthritis Rheum. 2005 Aug;52(8):2263-71.

21. Sibilia J, Westhovens R. Safety of T-cell costimulation modulation with abatacept in patients with rheumatoid arthritis. Clin Exp Rheumatol. 2007 Sep-Oct;25(5 Suppl 46):S46-56.

22. Salliot C, Finckh A, Katchamart W, Lu Y, Sun Y, Bombardier $\mathrm{C}$, et al. Indirect comparisons of the efficacy of biological antirheumatic agents in rheumatoid arthritis in patients with an inadequate response to conventional disease-modifying antirheumatic drugs or to an anti-tumour necrosis factor agent: a meta-analysis. Ann Rheum Dis. Feb;70(2):266-71.

23. Devine EB, Alfonso-Cristancho R, Sullivan SD. Effectiveness of biologic therapies for rheumatoid arthritis: an indirect comparisons approach. Pharmacotherapy. Jan;31(1):39-51.

24. Gallego-Galisteo M, Villa-Rubio A, Alegre-Del Rey E, Marquez-Fernandez E, Ramos-Baez JJ. 
Indirect comparison of biological treatments in refractory rheumatoid arthritis. J Clin Pharm Ther. Aug 10.

25. Leffers HC, Ostergaard M, Glintborg B, Krogh NS, Foged H, Tarp U, et al. Efficacy of abatacept and tocilizumab in patients with rheumatoid arthritis treated in clinical practice: results from the nationwide Danish DANBIO registry. Ann Rheum Dis. Jul;70(7):1216-22.

26. Singh JA, Wells GA, Christensen R, Tanjong Ghogomu E, Maxwell L, Macdonald JK, et al. Adverse effects of biologics: a network metaanalysis and Cochrane overview. Cochrane Database Syst Rev. (2):CD008794.

27. Curtis JR, Xie F, Chen L, Baddley JW, Beukelman T, Saag KG, et al. The comparative risk of serious infections among rheumatoid arthritis patients starting or switching biological agents. Ann Rheum Dis. Aug;70(8):1401-6.

28. Cimmino MA, Leardini G, Salaffi F, Intorcia M, Bellatreccia A, Dupont D, et al. Assessing the cost-effectiveness of biologic agents for the management of moderate-to-severe rheumatoid arthritis in anti-TNF inadequate responders in Italy: a modelling approach. Clin Exp Rheumatol. Jul-Aug;29(4):633-41.

29. Beresniak A, Ariza-Ariza R, Garcia-Llorente JF, Ramirez-Arellano A, Dupont D. Modelling costeffectiveness of biologic treatments based on disease activity scores for the management of rheumatoid arthritis in Spain. Int J Inflam.2011:727634. 